Sustainability 2015, 7, 6994-7010; doi:10.3390/su7066994

OPEN ACCESS

sustainability

ISSN 2071-1050

www.mdpi.com/journal/sustainability

Article

\title{
The Garbage Project Revisited: From a 20th Century Archaeology of Food Waste to a Contemporary Study of Food Packaging Waste
}

\section{La Vergne Lehmann}

School of Humanities, University of Adelaide, North Tce, 5005 Adelaide, Australia;

E-Mail: lavergne.lehmann@adelaide.edu.au; Tel.: +61-408-121-118

Academic Editors: Kirrilly Thompson, Drew Dawson and Anne Sharp

Received: 2 March 2015 / Accepted: 19 May 2015 / Published: 2 June 2015

\begin{abstract}
In 1973, Dr. Bill Rathje and his students at the University of Arizona began what was to become a two decade long investigation into American consumer waste habits. An archaeologist by profession, Rathje decided to adapt traditional archaeological methods and apply them to contemporary archaeological situations. This provided a platform for improving the understanding of what was really happening with, amongst other forms of waste, food at the consumer household level. The Garbage Project was able to study consumer behaviours directly from the material realities they left behind rather than from self-conscious self-reports of surveys and interviews. Using the same rationale, this study developed a profile of the packaged and processed food consumption in three regional Victorian municipalities. The main findings identified that consumers were limited to the food retail opportunities closest to their home and that they took greater care to wash out recyclables if they were placed in the recycling bin compared to the same item placed in a kerbside landfill bin. There was also an apparent lack of understanding about appropriate food storage and buying for purpose, especially with regard to the volume of the item they purchased, which appears to result in partially used recyclable containers being put in the kerbside landfill bin. By understanding the nature of the packaging and food that has been thrown away, it is possible to develop a narrative around what people understand about food purchasing practices, longevity, storage and how they use it at home. This in turn can assist community engagement and education around nutrition, meal planning and purchasing as well as community waste education.
\end{abstract}

Keywords: garbage project; food waste; contemporary archaeology 


\section{Introduction}

Changes to lifestyles, working habits, food health standards, labeling and food availability along with increased knowledge of different cultural food options have inevitably changed what and how people prepare, consume and consequently waste food. Recent waste audits and surveys in Victoria and New South Wales suggest that food makes up about 40 per cent of the contents in the household garbage bin. This translates into more than $\$ 1000$ of food waste per household each year or \$144 million in Victoria alone.

What is often missed in the analysis of food waste is what it can tell us about the changing nature of our food waste as a reflection of our diet. In decades past, our meals tended to be cooked from fresh raw ingredients. Today, our diets have become increasingly reliant on pre-prepared or partially prepared food. Thus, while we are producing more food waste, we are also producing more food packaging waste as well. This research provides the opportunity to understand what food waste and food packaging waste can tell us about current food consumption practices through the prism of what we dispose of in landfill waste and recycling.

Current research on household food waste and waste in general is largely based on two main sources of data; localised garbage bin audits and consumer surveys. The kerbside garbage bin audits have the capacity to provide the quantitative data needed to describe the contents and nature of our waste, while surveys can tell us whether consumers understand that we are producing too much waste. There are also problems with trying to measure food waste, in that households have other options for dealing with food waste including composting, worm farms, chickens and pets. Consequently, it is not easy to quantify to size of the food waste problem at the household level, as there is no consistent approach to disposal. In addition, previous survey results indicate that consumers cannot always explain how they wasted food; sometimes, they do not recognise that they are wasting food or may even be in denial about the food they waste. In short, the story we get from the audits does not always match the story provided by consumers.

Food packaging waste, however, is disposed of in a more consistent way; either as part of the landfill waste stream or recyclable stream and consequently can provide a lot of information about our changing dietary patterns.

Using the Garbage Project rationale, this study looks at three different municipal samples of general waste that was intended for landfill and recycling waste intended for a materials recycling facility (MRF) to develop a profile of the packaged and processed food consumption in three different Grampians municipalities. Once the nature of the packaged food has been identified, then analysis on what type of products were consumed, how they might have been consumed and how much was wasted, through the identification of the packaging and the food product that was not entirely used prior to disposal was undertaken.

By understanding the nature of the packaging and food that has been thrown away, it is possible to develop a narrative around what people understand about food purchasing practices, longevity, storage and how they use it at home. While this study is only capable of providing a brief foray into modern food purchasing, consumption and waste, it may assist in developing a direction for future research. Ultimately, if we better understand what consumers purchase and waste then better advice can be provided about food storage, use by and best by dates and portion sizes for purchase. This study has been limited to packaged and processed food items disposed of by the range of small communities with limited access to a retail options in their locale. 


\section{Using Contemporary Archaeology to Understand Waste}

In order to use archaeological methods to gain a better understanding of the consumption and waste in packaged food products in contemporary Australian society, it is first essential to understand why archaeological methods could be useful in this scenario. Wylie [1] explains that archaeology:

"could teach us about the conditions of life, the reasons for cultural change and persistence, affinity and diversity, that manifested themselves in the gritty particulars of the archaeological record.”

It is thus not unreasonable to think that archaeological methods could also be applied to research questions set in a contemporary environment. According to the Contemporary and Historical Archaeology in Theory (CHAT) Group, Contemporary Archaeology is an area of archaeological research that is most interested in the more recent past. The hallmark of contemporary archaeology is that it involves the application of archaeological thinking to the contemporary or modern world. It is often informed by anthropological material culture studies and is characterised by applying traditional archaeological methods and practices to new uses [2].

The reason for developing this branch of archaeology is to allow traditional archaeological methods to make a contribution to broader social scientific studies of the contemporary world. Methods can include the study of material things such as objects, landscapes, buildings and material heritage through to sociological, geographical and political studies of the modern world.

Schofield and Harrison [3] outline the main archaeological methods that can be used in a contemporary archaeology study. They suggest that while it is largely a matter of transferring traditional archaeological methods and skills, our cultural backgrounds and life experiences will potentially influence the way the material, which is often very familiar, is interpreted. There will also be differences in the natural decay, which because of the close temporal proximity, does not occur as readily in a contemporary setting. In the area of garbage, traditionally a rich source of material in archaeology studies, the fact that garbage is now regularly collected and transported to a specific location instead of being found in close proximity to the home or place of origin, changes the way that material can be interpreted.

The principle archaeological method that has been used in this study was artifact analysis. In the analysis of food packaging categories, the principle features were material and branding. There were also other complicating factors around the increasingly elaborate system of domestic recycling that means that similar items can end up in up to three completely separate waste streams. The type of information that was garnered from the material included the origin of the packaged food, how much was actually used, use by and best by dates, overall dietary habits and the amount and level of processed food in the total food waste stream.

Site surveys are another part of the traditional archaeological methods that could be applied. In this case, the location was around the nature of the waste stream in which the food item was found; general waste that went to landfill or recycling. This was an important feature in looking at packaged food products as it can potentially end up in either stream. This a finished container of tomato paste may be placed in recycling bin or place in the landfill waste bin depending on the type of packaging material whereas a partially finished jar may be thrown into the landfill waste bin because it contains food waste 
material. Thus, while it was not a site survey in the traditional sense, the same principles were applied to that site (i.e., the garbage bin).

\subsection{Using Archaeological Data to Confirm, Dispute or Refine Conventional Food Waste Research}

Traditional research methods to address these types of research questions include consumer surveys, interviews and focus groups. While these methods have some value, it is also true that most people tend to underestimate the amount of food waste that occurs in their household. However, using contemporary archaeological methods over a period of time can provide actual data on what and how much people waste.

Starting in 1973, Dr. William Rathje and his students at the University of Arizona initiated the Garbage Project [4-6]. Quantitative data from garbage bins was compared with information known about the residents who owned them. The results indicated that information people freely volunteered about their consumption habits did not always tally with the contents of their garbage bins. For example, alcohol consumption was proven to be significantly higher in reality than in the questionnaires completed by the people studied. Such findings have highlighted the difference between people's self-reported and actual behaviours [7-10].

What Rathje and his students did was to use archaeological methods in a modern setting. If archaeologists can learn important information about extinct societies from patterns in ancient garbage, then archaeologists should be able to learn important information about contemporary societies from patterns in fresh garbage (2). Dr. Timothy Jones has called this Contemporary Archaeology [11].

It was also the Garbage Project that was able to answer a key question in this research; why look at garbage? The reasons identified by the Garbage Project's founder, Dr. Bill Rathje were;

(1) The creation of garbage is an unequivocal sign of human presence and there is now an uninterrupted chain of garbage that stretches back more than two million years to the first "waste flake” taken off an early stone tool;

(2) If garbage can hold a key to our past, then surely it already holds a key to the present;

(3) Garbage is not an assertion or a claim but a physical fact. Keeping in mind that it still has to be interpreted, garbage can be used to either confirm or deny what other human evidence may claim [4].

Evans 2011 [12] study drew on ethnographic examples, exploring the dynamics of domestic food practices and considers their consequences in terms of waste. The study identified a number of key themes including: feeding the family; the concept of eating "properly"; the materiality of "proper" food and its intersections with the socio-temporal demands of everyday life and anxieties surrounding food safety and storage. Evans paid particular attention to the role of public health interventions in shaping the contexts through which food is at risk of wastage. Taken together, it is argued that household food waste cannot be conceptualised as a problem of individual consumer behaviour and suggest that policies and interventions might usefully be targeted at the social and material conditions in which food is provisioned.

Essentially, garbage represents a physical reality rather than folklore or mythology. Rathje reminds us that for each individual there are two realities; the mental reality, which encompasses beliefs, attitudes and ideas and the material reality, which is the picture developed from the physical record. The study of 
garbage has the capacity to provide evidence of what may be an alternate reality for many people as it may conflict with their mental reality.

\subsection{Recent Research about Food Waste in the Australian Community}

As we move into the 21st century and look towards planning for feeding a projected global population of more than nine billion people by 2075, the previously hidden problem of food waste has been highlighted. In a recent report by the Institution of Mechanical Engineers in the United Kingdom [13], it is stated that we currently produce about four billion metric tonnes of food per annum. However, as the result of poor practices in harvesting, storage and transportation, as well as market and consumer wastage, it is estimated that $30 \%-50 \%$ (or $1.2-2$ billion tonnes) of all food produced never reaches a human stomach.

While poor practices at the production end of the food supply chain are the main reasons for food waste in many developing nations, much of the waste in developed nations such as Australia occurs at the consumer end. Understanding why such waste occurs and how much occurs is one of the challenges in developing solutions to such a problem.

Contemporary research in Australia by both the New South Wales [14] and Victorian Governments [15] demonstrates that while there is some recognition that food waste is a problem in the community, it is not perceived to be their problem but rather a problem with "other" people. The basis for the concern about food waste has been physical bin audits that have shown that what people say and what they do are not always aligned. Waste audits conducted by NSW local councils indicated that food is the single largest component of the domestic kerbside waste stream (almost 38\% by weight). This translates to approximately 800,000 tonnes of food waste (or $315 \mathrm{~kg} /$ household/year) that goes to landfill across NSW every year [14]. In the study area for this research, the Grampians region [16] in western Victoria, a preliminary audit in June 2013 indicated that food waste made up 48\% of the general waste stream by weight, giving an average of 306.8 kilograms.

In Victoria [17], a majority (65\%) of respondents in a survey believed that packaging was the largest type of waste in their bin with $61 \%$ claiming they threw out very little food. Only $9 \%$ of residents indicated they threw out "more" or "much more" food than they should and $10 \%$ claimed they threw no food out at all.

Respondents were asked to estimate how much they felt the average Victorian household would spend on food that is never eaten on a yearly basis. The mean value of the estimates was $\$ 796$ per household per year. This figure tends to contradict the results given by respondents about their contribution to food waste and suggests that consumers are aware that the problem exists but do not acknowledge that they make a personal contribution to it. Similar results were found in NSW with the average value of food wasted by a typical NSW household [14] was found to be $\$ 1036$ per year, only $14 \%$ of respondents felt that they were throwing away more uneaten food than they should.

All of these figures demonstrate a clear difference between the understanding that consumers have about waste and the realities that are found during the process of a garbage audit. Such audits are undertaken so that waste reduction education programs can focus on the issues that are specific problems. However, the garbage audits can also provide even more information about what we consume and how 
we consume it. This has implications for food related health issues, nutrition education, cultural values of food and localized food consumption patterns.

\section{Results and Discussion}

While this audit activity began as a traditional garbage audit across the Grampians region in western Victoria, the opportunity arose to undertake a more detailed analysis of the food packaging and food waste that appeared in both the landfill waste and recyclables streams. According to Australian Bureau of Statistics (ABS) data, these areas are considered to be among the lower socio-economic areas in regional Victoria. It has also been recognised that there is a growing obesity issue in the region and that there is a lack of access to fresh and healthy food options. In all of these cases, the primary source of food for residents is the presence of one or two national supermarket chains in the larger towns of Ararat and Horsham and smaller independent grocery stores in the smaller towns.

\subsection{General Waste Stream Results}

A total of nine audits were conducted on 400 recycling and 400 general waste bins in Ararat, Horsham and Yarriambiack plus another 100 general waste bins in Moyston and Lake Bolac where they do not have a regular recycling service. All of these communities are located in the Grampians Regional Waste Management Group area in western Victoria as indicated in Figure 1.

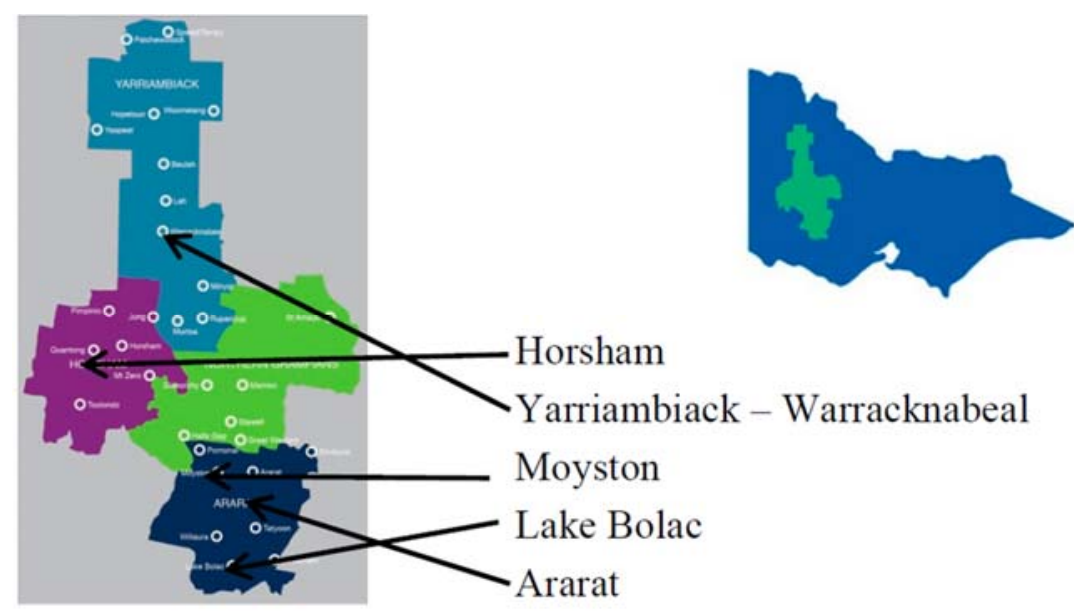

Figure 1. Map of the Grampians region and location of audits (www.Grampiansrwmg.vic.gov.au).

The communities range from very small populations of around 350 people in Moyston to a regional city like Horsham with a population of almost 16,000. Table 1 provides a summary of the overall number of bins collected during the course of the audit process. Participation rates relate to the number of bins presented at the designated household during the audit week. The lack of $100 \%$ participation is indicative of the type of demographic in the sample area where there is a higher than average proportion of single person or coupled households in the over 60-age group. This is also a demographic that tends to spend a higher proportion of their income on food related items rather than other household goods. 
Table 1. Presentation Rate-General Waste.

\begin{tabular}{ccccc}
\hline Date & Town & Sample & Collected & Participation\% \\
\hline 10 June 2013 & Horsham & 100 & 64 & $64 \%$ \\
9 October 2013 & Ararat & 100 & 77 & $77 \%$ \\
7 October 2013 & Yarriambiack & 100 & 84 & $84 \%$ \\
2 October 2013 & Moyston & 50 & 28 & $56 \%$ \\
3 October 2013 & Lake Bolac & 50 & 40 & $80 \%$ \\
- & Regional Total & 400 & 293 & $73 \%$ \\
\hline
\end{tabular}

As this study is only focusing on the portion of the overall collection that relates to food and food packaging, getting an overall understanding of the composition of the total regional sample is an important in developing the food and food packaging waste picture. Figure 2 indicates the overall waste categories as a percentage of the general waste composition. The important features in this diagram in terms of food waste are the organic compostable waste, glass, plastic, metal and paper. These features combined make up $65 \%$ of the overall general waste stream. Food waste alone is the organic compostable waste at $46 \%$ and the packaging features make up $19 \%$. This would indicate that current food consumption practices make up the vast majority of the waste stream in these communities.

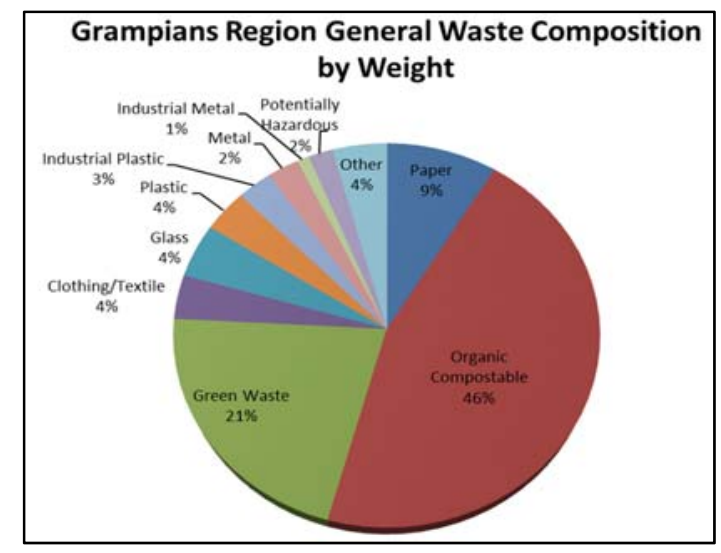

Figure 2. General waste composition by weight.

Table 2. Waste generation by household/week/year in kilograms.

\begin{tabular}{cccccccc}
\hline \multirow{2}{*}{ Council } & $\begin{array}{c}\text { General Waste } \\
\text { Residential } \\
\text { Tenements }\end{array}$ & $\begin{array}{c}\text { Participation } \\
\text { Rate }\end{array}$ & $\begin{array}{c}\text { Average } \\
\text { Bin } \\
\text { Weight }\end{array}$ & $\begin{array}{c}\text { Weekly Waste } \\
\text { Generation } \\
\text { Tonnes }\end{array}$ & $\begin{array}{c}\text { Annual Waste } \\
\text { Generation } \\
\text { Tonnes }\end{array}$ & $\begin{array}{c}\text { Household } \\
\text { Waste per } \\
\text { Week Kgs }\end{array}$ & $\begin{array}{c}\text { Household } \\
\text { Waste per } \\
\text { Year Kgs }\end{array}$ \\
\hline $\begin{array}{c}\text { Ararat } \\
\text { Horsham }\end{array}$ & 4362 & $82 \%$ & 10.3 & 36.8 & 1913.3 & 8.4 & 439 \\
Northern & 8241 & $64 \%$ & 14.5 & 76.7 & 3986.2 & 9.3 & 484 \\
Grampians & 5300 & $73 \%$ & 12.2 & 47.5 & 2469.2 & 9.0 & 466 \\
$\begin{array}{c}\text { Yarriambiack } \\
\text { Region }\end{array}$ & 3058 & $84 \%$ & 11.9 & 30.5 & 1585.9 & 10.0 & 519 \\
\hline
\end{tabular}

When this is broken down to the household level in each council area, Table 2 and Figure 3 presents the annual household waste in kilograms ranging from $439 \mathrm{~kg}$ in Ararat to $519 \mathrm{~kg}$ Yarriambiack. 


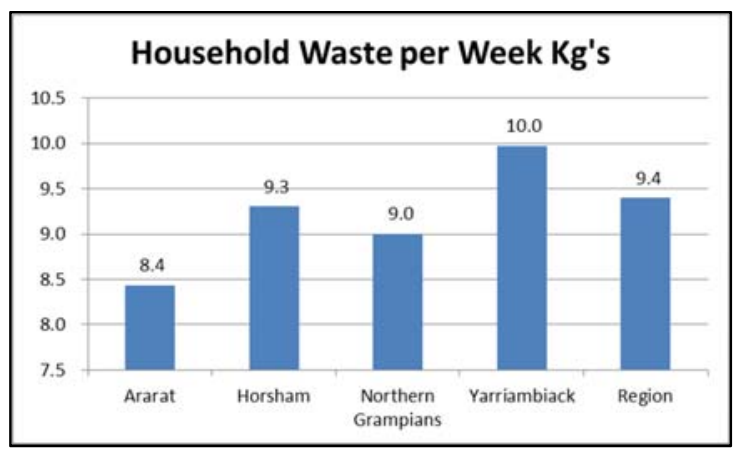

(a)

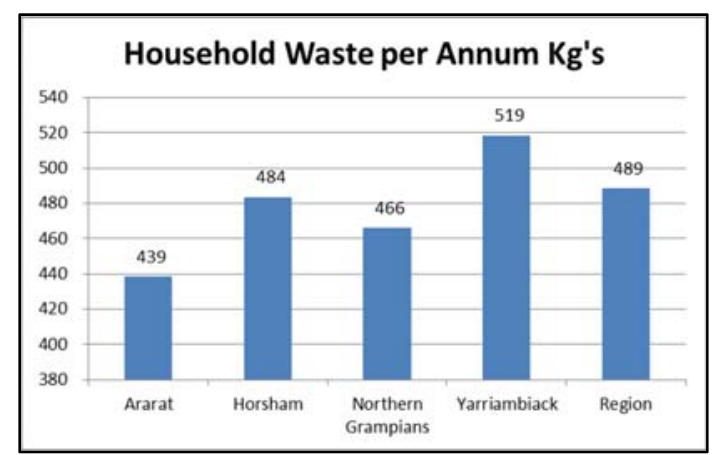

(b)

Figure 3. Household waste per week (a); and per annum in kilograms (b).

\subsubsection{Food Waste in the General Waste Stream}

Food waste is a critical feature in the total waste stream and relates to the overall packaging waste. The data relating to food waste across the region, described as organic compostable waste in the audit is presented in Table 3 (kilograms) and graphically in Figure 4. Food waste across the region ranges from a weekly low of 5 kilograms in Ararat to a high of 6.4 kilograms in Lake Bolac. Given the random nature of the audits across households in the region, it is not possible to draw many conclusions about the variation as there may have been a higher proportion of single or couple households in some samples compared to other areas where there may have been a higher proportion of families.

Table 3. Food waste disposed by household weekly (kilograms).

\begin{tabular}{cccc}
\hline $\begin{array}{c}\text { Food Waste Organic } \\
\text { Compostable by Weight }\end{array}$ & $\begin{array}{c}\text { Audit } \\
\text { Kgs }\end{array}$ & $\begin{array}{c}\text { Audit } \\
\text { Participants }\end{array}$ & $\begin{array}{c}\text { Weekly Waste } \\
\text { Generation Kilograms }\end{array}$ \\
\hline Horsham & 385 & $64 \%$ & 6.0 \\
Ararat & 386 & $77 \%$ & 5.0 \\
Yarriambiack & 523 & $84 \%$ & 6.2 \\
Moyston & 168 & $28 \%$ & 6.0 \\
Lake Bolac & 255 & $40 \%$ & 6.4 \\
Region & 344 & $58.6 \%$ & 5.9 \\
\hline
\end{tabular}

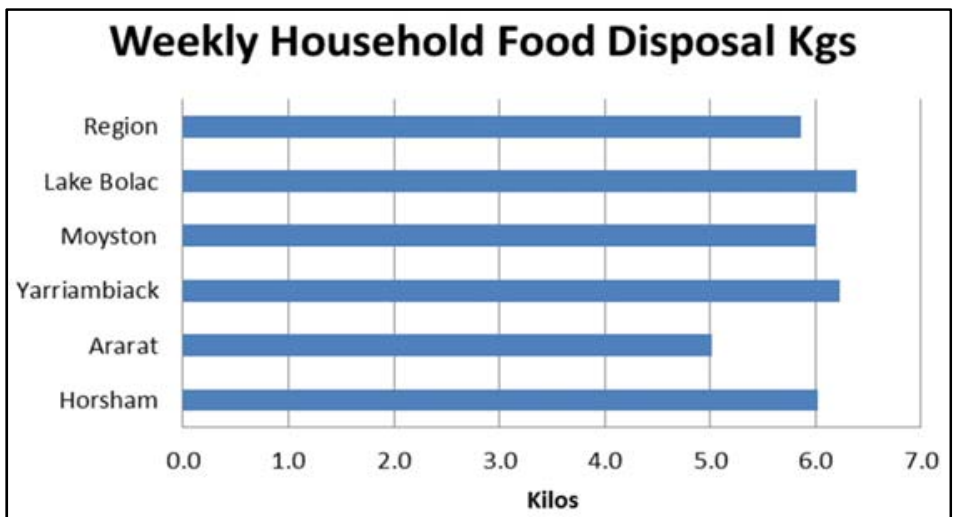

Figure 4. Weekly household food disposal in kilograms. 


\subsubsection{Food Packaging in the General Waste Stream}

Given that the focus of this research is on food packaging as well as food waste, analysis of the packaging within the general waste stream is essential. As previously noted, the majority of food packaging is now recyclable, with the exception of soft plastics, which is not recyclable in this region. However, within the general waste stream there is always a percentage of recyclate. These are items that should be in the recycling stream but have not been placed in the correct bin. Table 4 and Figure 5 summarise the level of recyclates across the region. In samples collected from each of the audits, the average level of food packaging in the general waste stream recyclate was $84.3 \%$ across the region.

Table 4. Recyclables disposed by household fortnightly.

\begin{tabular}{cccc}
\hline $\begin{array}{c}\text { Recyclate in General } \\
\text { Waste by Weight }\end{array}$ & $\begin{array}{c}\text { Audit } \\
\text { Kgs }\end{array}$ & $\begin{array}{c}\text { Audit } \\
\text { Participants }\end{array}$ & $\begin{array}{c}\text { Weekly Household } \\
\text { Disposal Kilograms }\end{array}$ \\
\hline Horsham & 135 & $64 \%$ & 2.1 \\
Ararat & 118 & $77 \%$ & 1.5 \\
Yarriambiack & 128 & $84 \%$ & 1.5 \\
Moyston & 118 & $28 \%$ & 4.2 \\
Lake Bolac & 226 & $40 \%$ & 5.7 \\
Region & 145 & $58.6 \%$ & 2.5 \\
\hline
\end{tabular}

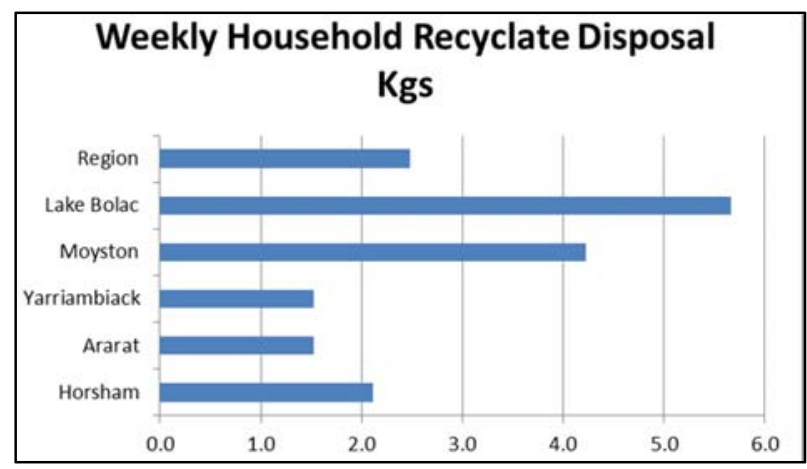

Figure 5. Weekly Household recyclate disposal.

The main items of interest for this research project in the general waste are those items that appear as food packaging. Lake Bolac and Moyston have not been included in this analysis as they do not have a recycling service and thus contain a far greater percentage of recyclate in their waste stream. In analysing ten 120 litre bin samples from each of Horsham, Yarriambiack and Ararat streams, food packaging was divided into glass, hard plastics, soft plastics, paper and cardboard and metals and percentage were calculated by volume. Soft plastics were not allocated a volume in the original analysis separate to overall plastic but have been separated for the purpose of this analysis. The following observations were made:

Glass (4\%)

- $42 \%$ of all glass in the waste stream was for alcohol related beverages.

- $58 \%$ of all food-related glass in the waste stream contained some form of waste food in the container.

- Those containers with more than half a container of food still in them had significant mould growth.

- $46 \%$ of the food in glass jars was after the best by date. 
- The most common food items in glass jars were pasta sauces (14\%), Asian style sauce mixes (9\%), taco sauces (6\%), tomato sauce (8\%), baby food (11\%) pickles and chutneys (6\%), jam or honey (9\%), sandwich spreads such as vegemite or peanut butter (10\%) and salad dressings (9\%).

- $\quad 75 \%$ of products were branded rather than supermarket house brand products.

Hard plastics (4\%)

- $\quad$ Food related plastics were $47 \%$ of the waste stream compared to $53 \%$ for beverage related items.

- Beverage related items included bottled water (18\%), cordial bottles (10\%), other soft drink bottles (14\%) and milk bottles (58\%).

- $32 \%$ of food related plastics contained some food still in the container with $80 \%$ being past the best by or use by dates.

- $\quad$ The most common containers were for large yoghurt (8\%), small yoghurt (17\%), margarine or butter (16\%), ice cream (3\%), cream (9\%), sour cream (5\%), salad dressings (8\%), fresh fruit and vegetable packaging (18\%) and meat trays (10\%).

- Food products with mould growing in them were almost entirely yoghurt or cream.

- Most plastic packaging was not squashed or flattened to fit into the bin.

Soft plastics—non-recyclable

- Almost no left over food found in this packaging with the exception of bread.

- The main items of packaging included bread bags, chip bags, biscuit packaging, nuts and snack packets, clear plastic inner packaging (non-identifiable but may come from packet cake or pudding mixes, cereal packets etc.), instant meals such as noodles, sauces, rice and past mixes, cling wrap plastics from meat or fruit and vegetable packaging, small sauce or dressing sachets, packaging for pasta, sugar, flour and rice.

Paper and cardboard packaging (9\%)

- Tetrapaks were the only beverage related products in this stream and made up $31 \%$ of the overall volume.

- $\quad$ Fast food packaging made up 8\% of the volume.

- No substantial food waste found in these items.

- Very little packaging flattened or squashed with items like cereal packets still containing inner plastic bags.

- Most common items were frozen pre-made meals such as pizza (12\%), single meal dinners (13\%), diet meals (12\%), cereal packets (16\%) with other categories including flour, sugar, cake mixes, chocolates, biscuit boxes.

Metal (2\%)

- $\quad 37 \%$ of the volume in this stream was beverage related and $90 \%$ was alcohol related.

- $6 \%$ of food containers had food still left in them. Only small amounts of food left in any containers and most of those that did contain food were either mouldy or dried out in the can.

- The main food items in the stream were canned soup, fruit, vegetables, fish or baked beans. 
The main observations that can be made about the data from the general waste stream are:

(1) There was less care given to the presentation of the items placed in the general waste stream than in the recycling stream. Empty containers tended not to be washed out if they were placed in the general waste. This is indicative of some success in education campaigns that encourage consumers to rinse out containers before placing them into recycling bins.

(2) A higher percentage of food waste was found within the containers in the general waste stream suggesting that people were less comfortable with the idea of putting partially full containers into their recycling or taking the trouble to empty them. The size of these containers suggests that the biggest problem was with larger containers or containers that were too large for the consumer to use within the required time frame. This could also relate the timing of recycling pickups, which are only fortnightly compared to weekly for general waste. This would suggest that there is a "yuk" factor associated with containerised food waste that may be in the bin because a deterioration process such as mould growth started prior to being placed in the bin.

(3) More than half the glass containers and a third of hard plastic containers still had some food in them. This suggests that consumers are unable, in the appropriate time frame, to use the entire contents of that container or have not stored the contents appropriately after opening. This could relate to a lack of understanding about good storage practices, purchasing an inappropriate size product or having tried a new product and deciding they did not like it. There are also suggestions that supermarkets promote the purchase larger size containers as a money saving method for families but when the same message is applied to smaller households could actually result in larger amounts of food waste.

(4) In looking only at packaged food it is clear that all the food waste there is avoidable unless it was already unfit for purpose at the time of sale. This would suggest that some householders do not plain their shopping and food consumption very well or are pushed into buying larger sizes at the local supermarket when they would prefer something smaller.

(5) As this is the first analysis of these waste streams it is not possible to consider trends in purchasing patterns. However some observations about the nature of purchases tended to indicate a significant level of interest in house brand products, pre-packaged complete single serve meals, smaller portion size products and diet meals for single servings. ABS data indicates that these areas are generally among the lower socio economic groups that would tend toward purchasing home brands in order to save money. The single serve meals are also indicative of a higher number of single person households, which is corroborated by the bin participation figures and the ABS household data.

\subsection{Recycling Stream Results}

The second part of the audits involved the collection and analysis of data for the recycling collections undertaken in various communities across the region. Recycling collections, as a rule, should not involve any direct food waste unless it is present as a contaminant. Unlike general waste streams, consumers are asked to rinse out containers that may have contained food or drink and if this regime is followed they are likely to contain little or no food waste. However, there is always some level of contamination in the recycling stream. It is also in the recycling stream that most food packaging is found as it most commonly 
contains glass, most forms of hard plastic, metals, paper and cardboard packaging. As demonstrated in Table 5 and Figure 6, the recycling participation rates are also less than $100 \%$ for similar reasons to those in the general waste stream. It should be noted that recycling is collected on a fortnightly basis and always in a 240-L bin.

Table 5. Recycling participation rates-Recyclate.

\begin{tabular}{lcccc}
\hline Date & Town & Sample & Collected & Participation \% \\
\hline 10 October 2013 & Horsham & 100 & 62 & $62 \%$ \\
10 October 2013 & Horsham & 100 & 78 & $78 \%$ \\
\multicolumn{2}{c}{ Horsham Total } & 200 & 140 & $70 \%$ \\
13 October 2013 & Yarriambiack & 100 & 74 & $74 \%$ \\
11 October 2013 & Ararat & 100 & 82 & $82 \%$ \\
\multicolumn{2}{c}{ Regional Total } & 400 & 296 & $74 \%$ \\
\hline
\end{tabular}

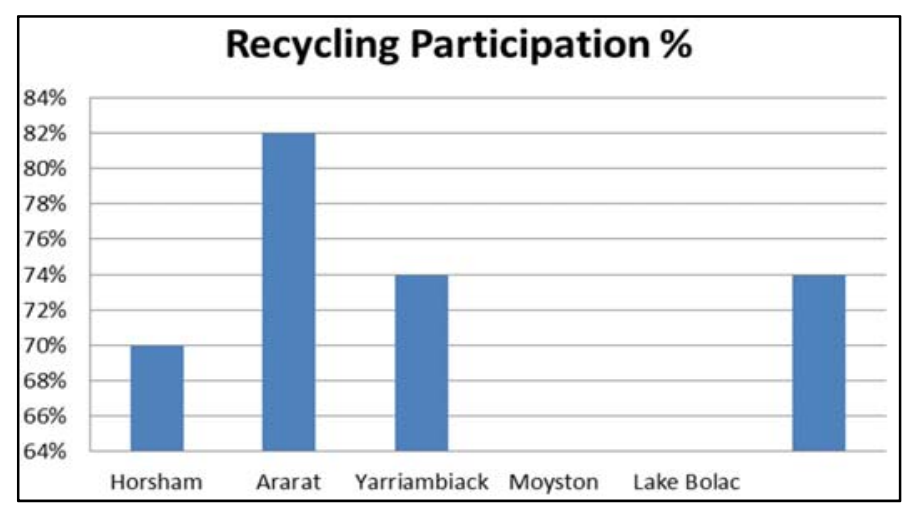

Figure 6. Recycling participation percentages.

One of the biggest issues with recycling is the level of contamination in kerbside recycling. In this audit, there was still $12 \%$ of organic compostable or food waste as indicated in Figure 7. Much of this waste appeared to be related to containers that still had too much food material in them to ensure that they could be successfully recycled.

The level of potential packaging recyclate is $80 \%$ with the combination of paper, metal, plastic and glass. A sample across the audits indicated that the overall level of food packaging was $72 \%$ with mostly paper being recycled from areas other than food packaging.

Table 6 and Figure 8 provide data on the level of recycling that is occurring across the region with Ararat clearly showing higher levels of recycling than any other area in the region. Horsham figures were particularly low, however, further investigation into the figures indicated that the areas targeted for the audit were known as poor recyclers and have been targeted specifically to look at measuring future improvements. 


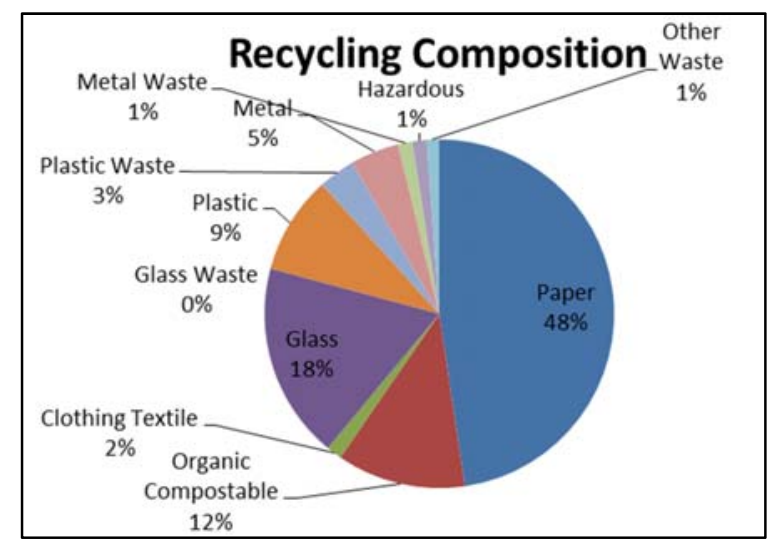

Figure 7. Recycling composition.

Table 6. Resource recovery per household/fortnight/year per kilogram.

\begin{tabular}{|c|c|c|c|c|}
\hline \multicolumn{2}{|c|}{ Council } & $\begin{array}{c}\text { Recycling } \\
\text { Residential }\end{array}$ & $\begin{array}{c}\text { Participation } \\
\text { Rate }\end{array}$ & $\begin{array}{c}\text { Average } \\
\text { Bin } \\
\text { Weight }\end{array}$ \\
\hline \multicolumn{2}{|c|}{ Ararat } & 3454 & $82 \%$ & 10.6 \\
\hline \multicolumn{2}{|c|}{ Horsham } & 6947 & $64 \%$ & 10.5 \\
\hline Northern & Grampians & 4800 & $74 \%$ & 10.5 \\
\hline \multicolumn{2}{|c|}{ Yarriambiack } & 3058 & $74 \%$ & 10.7 \\
\hline \multicolumn{2}{|c|}{ Region } & 18,259 & $75 \%$ & 10.61 \\
\hline \multicolumn{5}{|c|}{ Household Recyclate per Week Kg's } \\
\hline \multicolumn{5}{|l|}{9.0} \\
\hline \multicolumn{5}{|l|}{8.0} \\
\hline \multicolumn{5}{|l|}{7.5} \\
\hline \multicolumn{5}{|l|}{7.0} \\
\hline 6.5 & Ararat & Horsham & $\begin{array}{l}\text { Northern } \\
\text { Grampians }\end{array}$ & Region \\
\hline
\end{tabular}

(a)

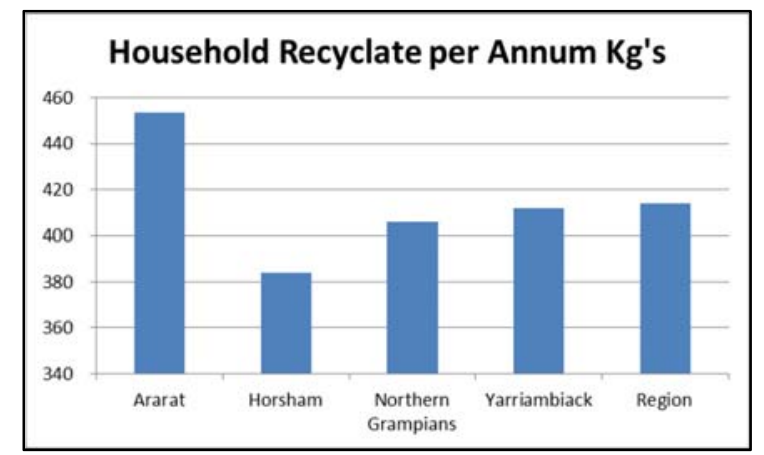

(b)

Figure 8. Household recyclate per week and per annum in kilograms.

In analysing ten $240 \mathrm{~L}$ bin samples from each of Horsham, Yarriambiack and Ararat, the various recyclate streams were divided the categories of glass, hard plastics, paper or cardboard and metal. The following observations were made:

Glass (18\%)

- $46 \%$ of all glass in the recycling stream was for alcohol related beverages.

- $54 \%$ of all glass in the recycling stream was for food related purposes.

- $8 \%$ of all food-related glass in the waste stream contained some form of waste food in the container. 
- $21 \%$ of the food in glass jars was after the best by date.

- $1 \%$ of glass jar containers had not been opened at all but were past the best by date.

- The most common food items in glass jars were pasta sauces (19\%), baby food (14\%), jam or honey (12\%), tomato sauce (9\%), sandwich spreads such as vegemite or peanut butter (9\%) Asian style sauce mixes mostly Chinese or Indian (8\%), salad dressings (8\%), taco sauces (7\%) and pickles and chutneys (4\%).

- $\quad 76 \%$ of products were branded rather than supermarket house brand products.

Hard Plastics (9\%)

- $\quad$ Food related plastics were $42 \%$ of the waste stream compared to $58 \%$ for beverage related items.

- Beverage related items included bottled water (12\%), cordial bottles (5\%), other soft drink bottles (15\%) and milk bottles (62\%).

- $15 \%$ of food related plastics contained some food still in the container with $72 \%$ being past the best by or use by dates.

- The most common containers were for fresh fruit and vegetable packaging (24\%) small yoghurt (21\%), margarine or butter (16\%), meat trays (14\%). salad dressings (9\%), cream (9\%), large yoghurt (6\%), sour cream (6\%) and ice cream (2\%).

- Food products with mould growing in them were almost entirely yoghurt or cream.

- Most plastic packaging was not squashed or flattened to fit into the bin.

Paper and cardboard packaging (48\%)

- $\quad$ Fast food packaging made up $15 \%$ of the volume of food packaging

- $\quad$ Tetrapaks for beverages made up $21 \%$ of the volume.

- Most packaging flattened or squashed with inner plastic bags removed.

- Most common items were frozen pre-made meals such as pizza (9\%), single meal dinners (16\%), diet meals (10\%), cereal packets (19\%) with other categories including flour, sugar, cake mixes, chocolates, biscuit boxes.

Metal (5\%)

- $\quad 46 \%$ of the volume in this stream was beverage related and $81 \%$ was alcohol related.

- $1 \%$ of food containers had food still left in them. In this case it was mostly aluminium foil trays that contained small amounts of food rather than cans.

- The main food items in the stream were aluminium food trays, foil, canned soup, fruit, vegetables, fish, baked beans or spaghetti.

Some observations from the data collected so far include:

(1) More effort has gone into presenting clean recyclates than items placed in the general waste stream. Plastic milk bottles in particular were extremely clean, indicating that they had been rinsed before disposal. This indicates that people perceive a distinct difference in the activity of recycling to that of throwing something into general waste. Recycling would appear to have a perceived value and is indeed valued by the consumer to the point where they ensure that their recyclables are cleaned. In contrast if something is going to landfill there is clearly no impetus to empty the container or clean it. 
(2) There is less wasted food still in the packaging in the recycling, indicating that perhaps people are emptying any food waste and cleaning the container prior to putting it into the recycling.

(3) Much higher proportions of alcoholic beverages found in the recycling stream, indicating that people are aware of the recyclability of glass and cans. It should be noted that this area does not have container deposit (CDL) opportunities, thereby making this a higher percentage of the recycling stream that in jurisdictions that have CDL.

(4) Pre-made processed food or dinner items appear as a significant category within the recycling stream. A significant proportion appeared to be low calorie diet meals, which may relate to seasonal factors and the promotion of weight loss programs in some local government areas where obesity is considered to be a significant problem.

(5) Clear semi-hard plastic containers used in supermarkets for fresh fruit and vegetables, pre-made salads, meat trays and for bakery items seem to be a significant category in the recycling stream. This confirms the source of much of the food that is consumed in the area as one of the major national supermarket chains rather than small independent stores.

\section{Conclusions}

In such a short research project, it is difficult gain any significant insights about the food packaging and food waste, purchasing and consumption habits. However, the results have shown that there is a significant amount of material available for future data collection and analysis. Looking at these figures over a longer period of time would also be of interest to see what, if any, changes are occurring in the food purchasing patterns of people in this region.

It should be noted that in most cases there are limited food purchasing options for people unless they choose to travel further afield and, while some may do that from time to time, it is unlikely that it occurs on a regular basis. In most communities, there are only one or two supermarket options available and three if they are in Horsham. There are also limited farmers markets around as most only have a monthly market at best. This would also suggest that there is a direct relationship between demographics, food shopping choices and food consumption. Thus, people will tend to purchase and consume what is presented to them in the most convenient way.

In considering this as a research topic in the first instance, it became quickly apparent that in looking at the packaged food items that appear in the waste stream that the vast majority of it would end up in the recycling stream rather than the general waste stream. However, it was interesting to note that there was significant difference in the presentation of items in each stream with items presented in the recycling in a much cleaner state than those in the general waste. One could assume that as the recyclable material would be re-used and the general waste was going straight to landfill that they would have considered that it was not worthwhile cleaning out any packaging. Equally there is some value placed on the recycling activity by people and a genuine belief that the items that they want to recycle are in fact recycled.

It was also clear that any leftover food in the containers was more likely to be found in the general waste stream rather than recycling. Again, a conclusion could be around the ultimate destination of the item being the critical factor. There were also indications that the majority of containers still containing 
food were in the large volume containers. Thereby, suggesting that the consumer may not have purchased the most appropriate size or smaller sizes were not generally available to them.

Some other areas that could be of interest into the future is the level of house brands that are appearing in the waste stream compared to branded products. While it is generally thought that supermarkets are pushing many of those items over branded versions, this analysis over time could confirm that.

In terms of material is apparent that with almost half the glass material being used in alcoholic beverage packaging now, that glass is less favoured as a food receptacle. Where once well-known brands would always be presented in glass, they are now being presented in glass-like plastic. This would suggest that producers understand that consumers perceive glass packaging as better quality. However, glass cost, transport costs and relatively low recycling returns for glass fines (broken glass in recycling) have now made a plastic glass lookalike a more attractive packaging option.

Pre-made dinners, and particularly diet versions also appear to be popular and again could be an interesting factor over time. Trends and fads in food consumption promoted by various television cooking shows, advertising campaigns or possibly even social media into the future could be interesting questions for the data that is generated from this type of research.

Whilst this study was limited in scope and location, the analysis found a clear differentiation with between the consumer attitude in their treatment of recyclable materials compared to landfill waste materials along with a lack of general understand about storage and buying for purpose. Following the work of material culture theorists like Daniel Miller [18], further ethnographic investigation of this empirical data needs to be undertaken to understand the socio-cultural, psychological and material processes underpinning the food waste behaviours from the pseudo-archaeological evidence reported in this paper. That is, to understand waste not simply as evidence of past human presence or human behaviours, but as an outcome of socio-cultural and material processes.

\section{Conflicts of Interest}

The author declares no conflict of interest.

\section{References}

1. Wylie, A. Thinking from Things, Essays in the Philosophy of Archaeology; University of California Press: Oakland, CA, USA, 2002.

2. Buchli, V.; Lucas, G. Archaeology of the Contemporary Past; Routledge: London, UK, 2002.

3. Schofield, J.; Harrison, R. After Modernity, Archaeological Approaches to the Contemporary Past; Oxford University Press: London, UK, 2010.

4. Rathje, W.L.; Murphy, C. Rubbish! The Archaeology of Garbage; The University of Arizona Press: Tucson, AZ, USA, 2001.

5. Rathje, W.L. Once and Future Landfills. Available online: http://infohouse.p2ric.org/ ref/31/30776.pdf (accessed on 21 May 2015).

6. Rathje, W.L. Rubbish! Atl. Mon. 1989, 246, 99-109.

7. Rathje, W.L.; Hughes, W.W.; Wilson, D.C.; Tani, M.K.; Archer, G.H.; Hunt, R.G.; Jones, T.W. The Archaeology of Contemporary Landfills. Am. Archaeol. 1992, 57, 437-447. 
8. Hughes, W.W. The Method to Our Madness: The Garbage Project Methodology. Am. Behav. Sci. 1984, 28, 41-50.

9. Rathje, W.L. The Garbàge Decade. Am. Behav. Sci. 1984, 28, 9-29.

10. Wilk, R.R.; Rathje, W.L. Household Archaeology. Am. Behav. Sci. 1982, 25, 617-639.

11. Jones, T.W. Using Contemporary Archaeology and Applied Anthropology to Understand Food Loss in the American Food System. Available online: http://www.ce.cmu.edu/ gdrg/readings/ 2006/12/19/Jones_UsingContemporaryArchaeologyAndAppliedAnthropologyToUnderstandFood LossInAmericanFoodSystem.pdf (accessed on 19 May 2015).

12. Evans, D. Blaming the consumer-Once again: The social and material contexts of everyday food waste practices in some English households. Crit. Public Health 2011, 21, 429-440.

13. Institution for Mechanical Engineers. Global food waste not, want not. Available online: http://www.imeche.org/knowledge/themes/environment/global-food (accessed on 29 May 2015).

14. NSW EPA. Food Waste Avoidance Benchmark Study; Environment Protection Authority: Sydney, Australia, 2012.

15. Audits of Household garbage and Recycling Bins 2013. Available online: http://www.tendersonline.com.au/TenderDetails.aspx?uid=cctol292443 (accessed on 21 May 2015).

16. Grampians Central West Waste and Resource Recovery Group. Available online: www.gcwwrrg.vic.gov.au (accessed on 29 May 2015).

17. Food Waste Avoidance Studies 2010. Available online: www.sustainability.vic.gov.au/ / media/resources/documents/publications\%20and\%20research/publications/c-\%20f/publications\% 20food\%20waste\%20avoidance\%20studies\%202010.pdf (accessed on 29 May 2015).

18. Miller, D. A Theory of Shopping; Cornell University Press: Ithaca, NY, USA, 1998.

(C) 2015 by the author; licensee MDPI, Basel, Switzerland. This article is an open access article distributed under the terms and conditions of the Creative Commons Attribution license (http://creativecommons.org/licenses/by/4.0/). 